\title{
Left ventricular function and oesophageal function in patients with angina pectoris and normal coronary angiograms
}

\author{
P M SCHOFIELD,* N H BROOKS, $S$ COLGAN, $\dagger$ D H BENNETT,*

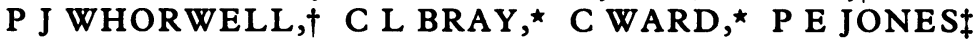 \\ From the Regional Cardiac Unit ${ }^{\star}$ and Department of Gastroenterology, $\ddagger$ Wythenshawe Hospital, Manchester; \\ and the Department of Gastroenterology, $\uparrow$ Withington Hospital, Manchester
}

SUMMARY Left ventricular function and oesophageal function (including oesophageal manometry and $\mathrm{pH}$ monitoring) were investigated and a psychiatric assessment carried out in 63 patients with angina pectoris and normal coronary angiograms. Twenty two (35\%) patients had regional abnormalities of left ventricular wall motion (group A). Thirty six (57\%) patients had an oesophageal abnormality (group B); 19 patients had gastro-oesophageal reflux and abnormal oesophageal motility, five had gastro-oesophageal reflux alone, and 12 had abnormal oesophageal motility alone. Only four had regional abnormalities of the left ventricular wall and abnormal oesophageal function. In nine $(14 \%)$ patients left ventricular and oesophageal function were normal (group C). Psychiatric morbidity was significantly less common in group A than in groups $B$ and $C$ and was similar in group $B$ and group $C$.

A definite abnormality of left ventricular function, oesophageal function, or psychiatric morbidity is present in a high proportion of patients with angina pectoris and normal coronary angiograms and in some instances this may lead to specific treatment. If quantitative assessment of left ventricular function is normal, oesophageal investigations should be performed. Endoscopy of the upper gastrointestinal tract may demonstrate oesophageal disease, but, if findings are normal, oesophageal manometry and ambulatory oesophageal $\mathrm{pH}$ monitoring (including during treadmill exercise testing) should be carried out.

Between $10 \%$ and $30 \%$ of patients referred for coronary angiography because of chest pain are found to have either normal coronary arteries or only minor narrowing of the coronary lumen. ${ }^{12}$ It has been suggested that many of these patients have a noncardiac cause for their chest pain, including oesophageal $^{34}$ and psychosomatic abnormalities. ${ }^{5}$ In 1974, Richardson et al reported seven patients in whom endomyocardial biopsy specimens showed features of congestive cardiomyopathy. ${ }^{6}$ We assessed left ventricular regional wall motion in 201 patients with angina pectoris and normal coronary angiograms and found that $35 \%$ had left ventricular

Requests for reprints to Dr P M Schofield, Regional Adult Cardiac Unit, Broadgreen Hospital, Thomas Drive,-Liverpool L14 3LB.

Accepted for publication 15 April 1987 systolic dysfunction. ${ }^{7}$ Oesophageal function and left ventricular function, however, have not previously been investigated in the same group of patients.

This prospective study was carried out on a series of patients presenting with typical angina pectoris who had completely normal coronary angiograms. Left ventricular function and oesophageal function, including oesophageal manometry and 24 hour oesophageal $\mathrm{pH}$ monitoring, were investigated. The patients were also assessed for evidence of psychiatric disorders.

\section{Patients and methods}

\section{PATIENTS}

We studied 63 consecutive patients (40 women and 23 men aged 30-68 (mean 47) years) with suspected coronary heart disease who had been referred to the 
Regional Cardiac Unit, Wythenshawe Hospital, between January 1985 and June 1986 but in whom coronary angiography was normal. All patients complained of recurrent exertional chest pain which was typical of angina pectoris in its site, character, and radiation. ${ }^{8}$ Their selective coronary angiograms, which had been performed in multiple views, were reviewed by three experienced observers and confirmed to be completely normal. Unlike many previous studies, we did not include patients with irregularities, even minor ones, on the coronary arteriogram. None of the patients had previously undergone any investigations of the gastrointestinal system.

\section{LEFT VENTRICULAR FUNCTION}

The left ventricular angiograms of all patients in this study showed satisfactory opacification of the chamber and the silhouettes could be traced. Only sinus beats that did not follow premature ventricular contractions were analysed. Three of the original 66 patients were excluded because their angiograms were not suitable for analysis. The left ventricular end systolic and end diastolic volumes and ejection fraction were calculated by the single plane arealength method after correction for magnification. ${ }^{9}$ Left ventricular regional wall motion was measured by the technique described by Leighton et al. ${ }^{10}$ The percentage of systolic shortening in seven hemiaxes $\left(\mathrm{H}_{1-7}\right)$ was calculated as previously described. ${ }^{7} \mathrm{~A}$ hypokinetic segment was defined as a hemiaxis where the percentage of systolic motion was $<2$ SD from the normal mean. ${ }^{10}$

\section{OESOPHAGEAL MANOMETRY}

We examined all patients by fibreoptic upper gastrointestinal endoscopy with oesophageal biopsy before the oesophageal motility study. Oesophageal manometry was performed on a different occasion with an Arndorfer hydraulic capillary infusion system linked to a Lectromed multichannel pen recorder. All medication was discontinued $\mathbf{4 8}$ hours before a standard oesophageal manometric study. ${ }^{1112}$ We measured the pressure of the lower oesophageal sphincter and the peristaltic activity of the oesophageal body in response to 10 "wet swallows" $\left(5 \mathrm{~cm}^{3}\right.$ water bolus). Sixty one of the 63 patients were then given $80 \mu \mathrm{g} / \mathrm{kg}$ of edrophonium chloride intravenously ${ }^{1314}$ and the manometric response was recorded, together with any symptoms experienced by the patients.

The recordings were analysed blindly and interpreted according to previously reported normal values. ${ }^{11} 121516$ Oesophageal manometric abnormalities included hypertensive lower oesophageal sphincter ( $\geqslant 30 \mathrm{~mm} \mathrm{Hg}$ ), "nutcracker" oesophagus (mean amplitude in distal oesophagus $\geqslant 120 \mathrm{~mm} \mathrm{Hg}$ or maximum amplitude $>200 \mathrm{~mm} \mathrm{Hg}$ or both), prolonged contractions (mean duration $\geqslant 6$ seconds), repetitive contractions (at least three peaks), simultaneous contractions (non-peristaltic), and manometric abnormalities associated with usual chest pain after intravenous edrophonium (positive edrophonium challenge).

\section{OESOPHAGEAL PH MONITORING}

The first 11 patients were referred for endoscopy and oesophageal manometry. Concern about possible undiagnosed gastro-oesophageal reflux prompted 24 hour ambulatory intra-oesophageal $\mathrm{pH}$ monitoring in the next 52 patients. ${ }^{17}$ All medication was discontinued 48 hours before and for the duration of this investigation. Patients were given a diary card to record the times of any symptoms and of eating, drinking, going to bed, and getting up. They activated an event marker at these times. During oesophageal $\mathrm{pH}$ monitoring the patients underwent symptom limited treadmill exercise testing by the standard Bruce protocol to determine whether exertional gastro-oesophageal reflux $(\mathrm{pH}<4)$ occurred.

The oesophageal $\mathrm{pH}$ record was analysed blindly, and a "score" was calculated as described by Johnson and DeMeester. ${ }^{18}$ This was derived by use of six components from the 24 hour oesophageal $\mathrm{pH}$ record, and a score greater than 21.3 was considered to be abnormal. ${ }^{18}$

\section{PSYCHIATRIC ASSESSMENT}

All patients were assessed by an experienced psychiatrist who did not know the results of cardiac catheterisation (apart from the presence of normal coronary angiograms) or the oesophageal investigations. The patients underwent a standardised psychiatric interview, including the Clinical Interview Schedule. ${ }^{19}$ The details of the psychiatric assessment will be published elsewhere, but for the purpose of this study patients were designated broadly as having a normal or abnormal psychiatric state. $^{5}$

\section{STATISTICAL ANALYSIS}

We examined group differences by a one-way analysis of variance and compared proportions by the $\chi^{2}$ test.

\section{Results}

In $41(65 \%)$ patients regional motion of the left ventricular wall was normal. The remaining $22(35 \%)$ patients had a total of 50 hypokinetic segments (group A): 10 had one hypokinetic segment, three 
Table 1 Oesophageal manometric abnormalities in 31 patients with angina pectoris and normal coronary angiograms

\begin{tabular}{|c|c|c|}
\hline Manometric abnormality & No of patients & Comment \\
\hline Repetitive contractions & $21^{\star}$ & 一 \\
\hline Prolonged duration of contractions & 19 & $\begin{array}{l}18 \text { had repetitive contractions, } \\
1^{\star} \text { had no other abnormality }\end{array}$ \\
\hline Simultaneous contractions & 10 & $\begin{array}{l}7 \text { had repetitive contractions, } \\
3^{\star} \text { had no other abnormality }\end{array}$ \\
\hline $\begin{array}{l}\text { Nutcracker oesophagus } \\
\text { Hypertensive lower oesophageal sphincter } \\
\text { Positive edrophonium challenge }\end{array}$ & $\begin{array}{l}3 \star \\
2 \\
6\end{array}$ & $\begin{array}{l}\text { Both had repetitive contractions } \\
3^{\star} \text { had no other abnormality, } \\
1 \text { had prolonged duration of contractions, } \\
1 \text { had simultaneous contractions, } \\
1 \text { had nutcracker oesophagus }\end{array}$ \\
\hline
\end{tabular}

ॠTotal of 31 patients with an oesophageal motility disorder.

had two, three had three, five had four, and one patient had five. Of the 50 hypokinetic segments, 24 were on the anterolateral wall $\left(\mathrm{H}_{1-4}\right)$ and 26 on the inferior wall $\left(\mathrm{H}_{5-7}\right)$. The mean (SD) left ventricular ejection fraction of patients with normal regional wall motion $(55.4(4.9) \%)$ was significantly higher than that of patients with hypokinetic segments $(43.8(5.7) \%)(\mathrm{p}<0.001)$.

In $28(44 \%)$ patients the results of oesophageal manometry were abnormal (table 1 ). The most common abnormality was repetitive oesophageal contractions which were usually associated with a prolonged mean duration of contractions. Figure 1 shows an example of a normal manometric study and fig. 2 is a trace from a patient with repetitive oesophageal contractions. In six $(10 \%)$ patients the usual chest pain developed when abnormal motility developed after intravenous edrophonium; however, three of them had an abnormal basal investigation. Therefore, a total of $31(49 \%)$ patients had abnormal oesophageal motility.

Eleven $(21 \%)$ patients had an abnormally high 24 hour oesophageal pH score. ${ }^{18}$ Ten of these patients had gastro-oesophageal reflux during treadmill exercise testing. In nine of them reflux was associated with their usual chest pain. A further $13(25 \%)$ patients had a normal 24 hour $\mathrm{pH}$ score but experienced chest pain coincident with gastro-oesophageal reflux during exercise testing. In each case, the onset of chest pain occurred between one and four minutes after the development of gastro-oesophageal reflux and resolved completely within five minutes of the oesophageal $\mathrm{pH}$ returning to $>4$. These $24(46 \%)$ patients were considered to have gastro-oesophageal reflux disease. ${ }^{17}$ Nineteen of these 24 patients also had abnormal oesophageal motility (table 2 ). Eleven

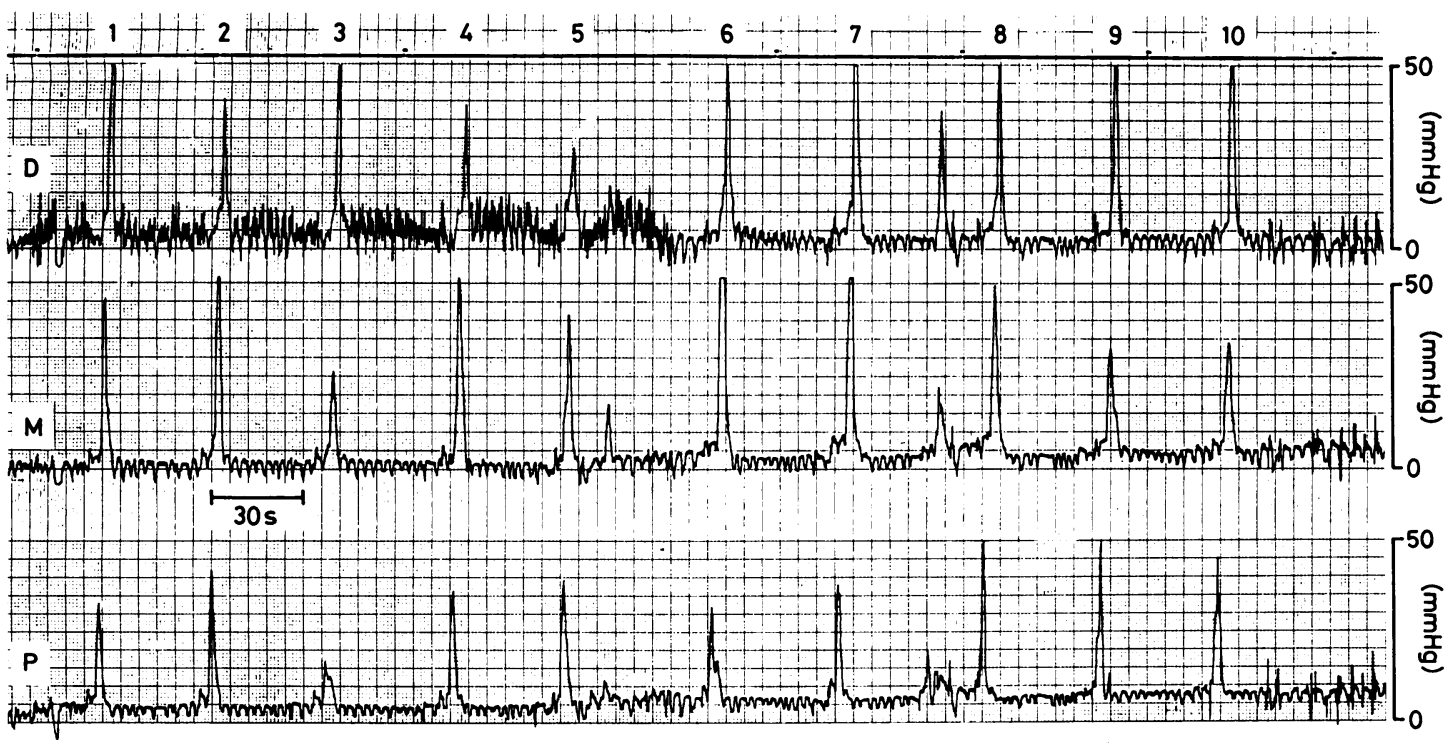

Fig 1 Normal oesophageal motility with peristaltic contractions of normal amplitude and duration in response to 10 wet swallows. $D$, distal oesophageal manometer; $M$, middle oesophageal manometer; $P$, proximal oesophageal manometer. 


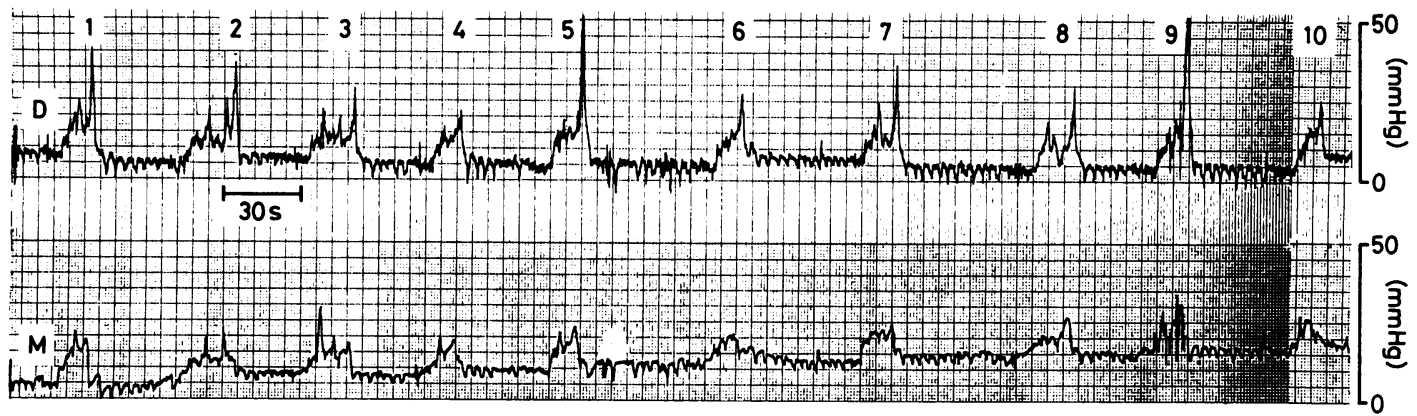

Fig 2 Abnormal oesophageal motility with repetitive contractions of abnormally long duration ( $>6 s$ ) in response to 10 wet swallows. $D$, distal oesophageal manometer; $M$, middle oesophageal manometer.

$(46 \%)$ patients with gastro-oesophageal reflux disease had both macroscopical and microscopical evidence of oesophagitis and one patient had microscopical evidence of oesophagitis. One patient with a normal oesophageal $\mathrm{pH}$ investigation was found to have macroscopical and microscopical oesophagitis and a further two patients had microscopical oesophagitis; all three patients had abnormal oesophageal manometry.

An oesophageal abnormality was therefore demonstrated by manometry or $\mathrm{pH}$ monitoring in 36 $(57 \%)$ (group B) of the 63 patients studied. In 19 patients both investigations were abnormal, in five patients only the $\mathrm{pH}$ monitoring was abnormal, and in 12 patients only the manometry was abnormal (including five of the 11 patients who did not undergo oesophageal $\mathrm{pH}$ monitoring). Four patients with an oesophageal abnormality also had abnormal regional motion of the left ventricular wall. Only nine (14\%) patients (group C) had normal left ventricular function and normal oesophageal $\mathrm{pH}$ and manometry.

Table 3 shows the results of the psychiatric assessment. Twenty seven $(43 \%)$ of the 63 patients in the study were assessed as having a psychiatric disorder. Psychiatric morbidity was significantly less common in patients with left ventricular regional wall motion abnormalities than in patients with an oesophageal abnormality $(p<0.01)$ and patients with normal left ventricular and oesophageal function $(p<0.05)$.
There was no difference, however, in psychiatric morbidity between patients with oesophageal abnormalities and those with normal left ventricular and oesophageal function.

\section{Discussion}

Previous investigators of patients with "noncardiac" chest pain have suggested that in some cases symptoms are caused by an oesophageal disorder, including abnormal oesophageal motility ${ }^{20-24}$ and gastro-oesophageal reflux. ${ }^{25} 26$ Others have demonstrated a high frequency of psychiatric morbidity ${ }^{5}$ and we have recently confirmed that some patients have evidence of left ventricular dysfunction. ${ }^{7}$ Oesophageal function, left ventricular function, and psychiatric assessment have not previously been examined in the same group of patients. Unlike the present investigation, many previous studies have included patients with atypical chest pain and patients who had not been demonstrated to have completely normal coronary angiograms.

We found that $35 \%$ of patients had left ventricular regional wall motion abnormalities; this resembles our previous experience. ${ }^{7}$ We found that regional abnormalities of wall motion were extremely uncommon in a control group of patients who did not complain of chest pain and had normal coronary angiograms but who did have trivial aortic valve disease. ${ }^{7}$ The patients with angina pectoris

Table 2 Results of oesophageal manometry and endoscopy in 52 patients who underwent oesophageal pH monitoring

\begin{tabular}{|c|c|c|}
\hline & Oesophageal manometry & Endoscopy of upper gastrointestinal tract \\
\hline Gastro-oesophageal reflux disease $(n=24)$ & 19 abnormal manometry & $\begin{array}{l}11 \text { macroscopical and microscopical } \\
\text { oesophagitis }\end{array}$ \\
\hline Normal oesophageal pH study $(n=28)$ & $\begin{array}{l}5 \text { normal manometry } \\
7 \text { abnormal manometry } \\
21 \text { normal manometry }\end{array}$ & $\begin{array}{l}1 \text { microscopical oesophagitis } \\
1 \text { macroscopical and microscopical } \\
\text { oesophagitis } \\
2 \text { microscopical oesophagitis }\end{array}$ \\
\hline
\end{tabular}


Table 3 Psychiatric assessment in 63 patients with angina pectoris and normal coronary angiograms

\begin{tabular}{lll}
\hline Description & Group & Psychiatric assessment \\
\hline Patients with left ventricular wall motion abnormality $(n=22)$ & A & 4 with psychiatric abnormality, \\
Oesophageal abnormality (pH and/or manometry) $(n=36)$ & B & 18 without \\
Normal left ventricular and oesophageal function $(n=9)$ & C & 17 with psychiatric abnormality, ${ }^{\star}$ \\
& & 5 with psychiatric abnormality, $\dagger$ \\
\hline
\end{tabular}

* Significantly different from group $A, p<0.01$.

+ Significantly different from group $A, p<0.05$.

and normal coronary angiograms who had left ventricular dysfunction, demonstrated features during treadmill exercise testing that were suggestive of myocardial ischaemia ${ }^{7}$; they had a reduced exercise capacity, ${ }^{27}$ were more likely to experience chest pain, ${ }^{28}$ and had an abnormal ST segment response at an earlier stage of exercise ${ }^{29}$ than those with normal left ventricular function. Patients with congestive cardiomyopathy often complain of chest pain, despite the presence of normal or large coronary arteries, and they have been found to have reduced coronary blood flow at rest and during cardiac pacing. ${ }^{30}$ No patient in this series had clinical or radiological evidence of cardiac failure. The patients with left ventricular dysfunction were distinct from those with an oesophageal abnormality; only four $(6 \%)$ patients had both disorders demonstrated.

Although the results of oesophageal manometry were abnormal in many patients with non-cardiac chest pain, ${ }^{20-24}$ it has proved difficult to establish a temporal relation between symptoms and the abnormality. This has led to the use of provocation procedures to induce the simultaneous occurrence of chest pain and oesophageal dysmotility; intravenous edrophonium is probably the safest and most effective of these procedures. ${ }^{1314} \mathrm{~A}$ temporal relation with symptoms was established in $24(67 \%)$ of the 36 patients in this study who had an oesophageal abnormality. In the remaining 12 patients the abnormalities only suggested that the oesophagus was responsible ${ }^{20}$ for the chest pain. As well as provocation with intravenous edrophonium during oesophageal manometry we found that treadmill exercise testing during oesophageal $\mathrm{pH}$ monitoring helped to confirm the association between symptoms and gastro-oesophageal reflux. ${ }^{17}$ The mere presence of an oesophageal abnormality does not indicate a definite causal relation with the patient's chest pain. ${ }^{31}$ Although some studies indicate that disordered oesophageal motility is common in patients with coronary artery disease,,$^{32} 33$ these were studies of small numbers of patients who had oesophageal symptoms $\mathrm{s}^{33}$ and had chest pain other than angina pectoris. $^{32} \mathrm{We}$ investigated patients with angina pectoris and coronary artery disease and found a low prevalence of oesophageal motility disorder $(<10 \%$, unpublished results). This result increases the likelihood that there is a causal relation in those patients in whom the oesophagus is suspected as a cause of chest pain.

There was no evidence of coronary artery spasm in patients in the present study; however, this is rare in patients with normal coronary arteries ${ }^{34}$ and usually produces rest pain rather than exertional chest pain. ${ }^{35}$ Rasmussen et al have recently demonstrated oesophageal spasm in a small number of patients with coronary artery spasm; some of their patients had important coronary artery disease. ${ }^{36}$

In the present study endoscopy of the upper gastrointestinal tract with oesophageal biopsy found evidence of oesophagitis in $50 \%$ of patients who had an abnormality of gastro-oesophageal reflux demonstrated by intra-oesophageal $\mathbf{p H}$ monitoring. This is similar to the experience of DeMeester et al ${ }^{25}(39 \%)$ and de Caestecker et $\mathrm{al}^{26}(38 \%)$ and indicates that endoscopy is of limited sensitivity in detecting gastro-oesophageal reflux disease.

Only nine (14\%) patients in this series had normal left ventricular function and normal oesophageal $\mathrm{pH}$ and manometry. Twenty seven $(43 \%)$ of the 63 patients had psychiatric morbidity. Bass et al assessed psychiatric morbidity in patients with and without coronary artery disease. ${ }^{3738}$ Twenty eight $(61 \%)$ of 46 patients with normal or near normal coronary arteries had psychiatric morbidity compared with $12(23 \%)$ of 53 patients with important coronary artery disease $(>50 \%$ obstruction in one or more vessels). They suggested that psychiatric morbidity in patients with normal or slightly diseased coronary arteries was more likely to be a cause rather than a consequence of chest pain. In this study, psychiatric morbidity was significantly less common in patients with left ventricular dysfunction than in patients with an oesophageal abnormality or patients with normal oesophageal function 
and normal left ventricular function. The presence of psychiatric morbidity does not, however, exclude the possibility of a left ventricular, an oesophageal, or both abnormalities as the cause of chest pain.

Our findings indicate that patients with typical angina pectoris and completely normal coronary angiograms are heterogeneous in terms of the cause of their symptoms, and that a definite abnormality can be detected in a high proportion. If quantitative assessment of left ventricular function is normal oesophageal disease should be sought. We recommend endoscopy of the upper gastrointestinal tract, and that if no abnormality is detected oesophageal manometry and ambulatory oesophageal $\mathrm{pH}$ monitoring (including during treadmill exercise testing) should be performed. A similar policy was advised by de Caestecker et al, ${ }^{26}$ whereas others have suggested that a psychiatric cause should be considered before oesophageal investigations are undertaken. ${ }^{31}$ We hope that accurate diagnosis will lead to effective treatment.

The work described is part of a study that will be submitted by PMS to the University of Manchester for the degree of Doctor of Medicine.

We thank Mrs J Clarke, Mrs R Dodd, and Mrs D Massey for their help with the oesophageal investigations.

\section{References}

1 Kemp HG, Vokonas PS, Cohn PF, Gorlin R. The anginal syndrome associated with normal coronary arteriograms: report of a six year experience. $A m \mathrm{~J}$ Med 1973;54:735-42.

2 Marchandise B, Bourassa MG, Chaitman BR, Lesperance J. Angiographic evaluation of the natural history of normal coronary arteries and mild coronary atherosclerosis. Am J Cardiol 1978;41:216-20.

3 Benjamin SB, Castell DO. Chest pain of oesophageal origin. Arch Intern Med 1983;143:772-6.

4 Davies HA, Jones DB, Rhodes J. "Oesophageal angina" as the cause of chest pain. JAMA 1982;248:2274-8.

5 Bass C, Wade C, Hand D, Jackson G. Patients with angina with normal and near normal coronary arteries: clinical and psychological state 12 months after angiography. Br Med $J$ 1983;287:1505-8.

6 Richardson PJ, Livesley B. Oram S. Angina pectoris with normal coronary arteries. Transvenous myocardial biopsy in diagnosis. Lancet 1974;ii:677-80.

7 Schofield PM, Brooks NH, Bennett DH. Left ventricular dysfunction in patients with angina pectoris and normal coronary angiograms. Br Heart $J$ 1986;56: 327-33.

8 Master AM. The spectrum of anginal and non-cardiac chest pain. JAMA 1964;187:894-9.

9 Rackley CE. Quantitative evaluation of left ventricular function by radiographic techniques. Circulation 1976;54:862-79.
10 Leighton RF, Wilt SM, Lewis RP. Detection of hypokinesis by a quantitative analysis of left ventricular cineangiograms. Circulation 1974;50:121-7.

11 Benjamin SB, Gerhardt DC, Castell DO. High amplitude, peristaltic esophageal contractions associated with chest pain and/or dysphagia. Gastroenterology 1979;77:478-83.

12 Benjamin SB, Castell DO. Chest pain of esophageal origin. Where are we, and where should we go? Arch Intern Med 1983;143:772-6.

13 Benjamin SB, Richter JE, Cordova CM, Knuff TE, Castell DO. Prospective manometric evaluation with pharmacologic provocation of patients with suspected oesophageal motility dysfunction. Gastroenterology 1983;84:893-901.

14 London RL, Ouyang A, Snape WJ, Goldberg S, Hirschfield JW, Cohen S. Provocation of oesophageal pain by ergonovine or edrophonium. Gastroenterology 1981;81:10-4.

15 Nelson JL, Wu WC, Richter JE, Blackwell JN, Johns DN, Castell DO. What is normal oesophageal motility? [Abstract]. Gastroenterology 1983;84:1258.

16 Berger K, McCallum RW. The hypertensive lower oesophageal sphincter: a clinical and manometric entity [Abstract]. Gastroenterology 1981;80:1109.

17 Schofield PM, Bennett DH, Jones PE, et al. Exertional gastro-oesophageal reflux. A mechanism for symptoms in patients with angina pectoris and normal coronary angiograms. $\mathrm{Br} \mathrm{Med} J$ 1987;294:1459-61.

18 Johnson LF, DeMeester TR. Twenty-four-hour pH monitoring of the distal esophagus. A quantitative measure of gastro-oesophageal reflux. Am J Gastroenterol 1974;62:325-32.

19 Goldberg DP, Cooper B, Eastwood MR, Kedward HB, Shepherd M. A standardized psychiatric interview for use in community surveys. Br $\mathrm{J}$ Prev Soc Med 1970;24:18-23.

20 Brand DC, Martin D, Pope CE. Esophageal manometrics in patients with angina-like chest pain. Dig Dis Sci 1977;22:300-4.

21 Svensson O, Stenport G, Tibbling L, Wranne B. Oesophageal function and coronary angiogram in patients with disabling chest pain. Acta Med Scand 1978;204:173-8.

22 Ferguson SC, Hodges K, Hersh T, Jinich H. Esophageal manometry in patients with chest pain and normal coronary arteriogram. Am J Gastroenterol 1981;75:124-7.

23 Kline M, Chesne R, Sturdevant RA, McCallum RW. Esophageal disease in patients with angina-like chest pain. Am J Gastroenterol 1981;75:116-23.

24 Patterson DR. Diffuse oesophageal spasm in patients with undiagnosed chest pain. J Clin Gastroenterol 1982;4:415-7.

25 DeMeester TR, O'Sullivan GC, Bermudez G, Midel AI, Cimochowski GE, O'Drobinak J. Esophageal function in patients with angina-type chest pain and normal coronary angiograms. Ann Surg 1982;196:488-98.

26 de Caestecker JS, Blackwell JN, Brown J, Heading RC. The oesophagus as a cause of recurrent chest pain: which patients should be investigated and which tests should be used? Lancet 1985;ii:1143-6. 
27 Calvert AF, Bernstein L, Bailey IK. Physiological responses to maximal exercise in a normal Australian population: comparative values in patients with anatomically defined coronary artery disease. Aust NZJ Med 1977;7:497-506.

28 Cole JP, Ellestad MH. Significance of chest pain during treadmill exercise: correlation with coronary events. Am J Cardiol 1978;41:227-32.

29 Kansal S, Roitman D, Bradley EL, Sheffield LT. Enhanced evaluation of treadmill tests by means of scoring based on multivariate analysis and its clinical application: a study of 608 patients. Am J Cardiol 1983;52:1155-60.

30 Pasternac A, Noble J, Streulens Y, Elie R, Henschke C, Bourassa MG. Pathophysiology of chest pain in patients with cardiomyopathies and normal coronary arteries. Circulation 1982;65:778-89.

31 Channer KS. Oesophageal abnormalities in patients with chest pain. Lancet 1986;i:42-3.

32 Brand DL, Martin D, Pope CE. Esophageal man- ometrics in patients with angina-like chest pain. Dig Dis Sci 1977;22:300-4.

33 Tibbling $\mathrm{L}, \mathrm{W}$ ranne B. Oesophageal dysfunction in male patients with angina-like pain. Acta Med Scand 1976;200:391-5.

34 Ginsburg R. Coronary artery spasm: clinical experience and implications. Hosp Pract 1983;18:165-76.

35 Mark DB, Califf RM, Morris KG, et al. Clinical characteristics and long-term survival of patients with variant angina. Circulation 1984;69:880-8.

36 Rasmussen K, Ravnsbaek J, Funch-Jensen P, Bagger JP. Oesophageal spasm in patients with coronary artery spasm. Lancet 1986;i:174-6.

37 Bass C, Wade C. Chest pain with normal coronary arteries: a comparative study of pyschiatric and social morbidity. Psychol Med 1984;14:51-61.

38 Bass C, Wade C, Gardner TN, et al. Unexplained breathlessness and psychiatric morbidity in patients with normal and abnormal coronary arteries. Lancet 1983;i:605-9. 